Journal of Mechanical Engineering and Sciences

ISSN (Print): 2289-4659; e-ISSN: 2231-8380

Volume 12, Issue 2, pp. 3581-3592, June 2018

(C) Universiti Malaysia Pahang, Malaysia

DOI: https://doi.org/10.15282/jmes.12.2.2018.5.0317

\title{
Investigation of Axial Misalignment Effects to the Gear Tooth Strength Properties Using FEM Model
}

\author{
M.R.Lias ${ }^{1,2 *}$, M.Awang', M.N.Talib ${ }^{1}$, A.R.Senawi ${ }^{2}$, M.A.Samad ${ }^{1}$ \\ ${ }^{1}$ Department of Engineering and Skills, Kluang Community College, \\ Ministry of Higher Education Malaysia, \\ 86000 Kluang, Johor, Malaysia \\ *Email: mohdrizal.lias@kkkluang.edu.my \\ Phone: +6 07773 3505; Fax: +6077733602 \\ ${ }^{2}$ Department of Mechanical Engineering, Faculty of Engineering, \\ Universiti Teknologi PETRONAS, \\ Bandar Seri Iskandar, 31750 Tronoh, Perak, Malaysia
}

\begin{abstract}
Misalignment between gear teeth is well-known to affect the strength properties of the gears. Despite many models proposed in research domain, investigations of the strength properties of a gear in axial misalignments condition are limited or yet to be discovered. In this study, an axial misalignment effects upon the strength properties of tooth surface contact stress and tooth root bending stress were discussed. A three tooth gear model was constructed based on a physical problem of two involute spur gears using an Autodesk Inventor gear design generator. The model was exported and analysed according to quasi-statics approach using a finiteelement method. Initially, the model was verified by comparing to the previous studies. The same models were then attached to a set of drive constraint misalignment plane, where a parametric study of the axial misalignments $0.1 \mathrm{~mm}, 0.2 \mathrm{~mm}, 0.3 \mathrm{~mm}, 0.4 \mathrm{~mm}$ and $0.5 \mathrm{~mm}$ was investigated. In general, results showed that axial misalignments do impact upon strength the strength properties of the gears. Tooth surface contact stress and tooth root bending stress showed between $5 \%$ to $15 \%$ incremental trend at different critical location while the strength reducing simultaneously with the application of axial misalignments. The pinion showed a weakening trend compare to the wheel when the application of axial misalignments took place. A series of verification tests was suggested to validate the finite-element model thus concluded that this research had achieved its main objectives where the strength properties of tooth surface contact stress and tooth root bending stress of the gear in axial misalignments gear were successfully investigated.
\end{abstract}

Keywords: FEM modeling; tooth root; bending stress; tooth surface; contact stress; strength properties.

\section{INTRODUCTION}

Gears are toothed wheels, which have been used for about 3000 years [1]. It was invented to transmit circular motion and rotational force from one part to another in mechanical machines. Today, gears are used in many machinery systems with various range of sizes and materials. It is practically used in pairs by attaching them to a shaft. When the two gears are meshed, rotation from the drive gear called pinion causes the driven gear called wheel to rotate and transmit power. The classification of gear pair is according to their relative positions on the axis of revolution, where the intersection between the parallel or non-parallel gear's tooth mesh takes 
place. The gears that have parallel shafts are spur, helical and herringbone gears; while the nonparallel shafts are bevel and spiral gears.

In general, spur gears are much preferable in many transmission systems. Perhaps, it is the most reliable type of parallel axis gear that is capable of generic maximum strength and lifting forces [2]. The straight perpendicular teeth to its side flat surface makes the spur gear the easiest types to be fabricated. The spur gear teeth may be hobbed, shaped, milled, stamped, drawn, sintered, cast or shear cut. They may give a finishing operation with such as grinding or shaving. Generally, there are more kinds of machine tools and process available to fabricate spur gear than other types of gears [1]. This accessibility often makes spur gear as the main choice of the gear design in the transmission system.

The design of spur gears were dictated by various system-level requirements established for the power transmission system. These requirements are set to achieve increased levels of durability and reliability; power density (power-to-weight ratio) while reducing cost; and noise levels as well as power losses of the drive train. Gear design concepts that can deliver functional attributes to meet these multiples and often conflicting, requirements cannot be achieved by using conventional design formulae. Advanced computational models such as FEM are often required to arrive at designs while satisfying these stated requirements [3].

Besides functionality, durability and reliability of the gear pair is especially critical. Requirements such as noise and efficiency are rather irrelevant if the gear set fails to endure the life cycles it is designed for. Spur gears life cycles are determined according to the strength of its design teeth. Gear fatigue failures can occur in two distinct forms. One type is the contact fatigue failure, resulting in deterioration of the contacting tooth surfaces due to micro-pitting or spalling. This type of failure is dependent on a number of lubrication, load, speed and surface related parameters. Another common type of fatigue failure in gears is the tooth bending fatigue failure. This failure is more catastrophic than the contact failures as a broken tooth halts the operation of the drive train immediately. Such failures are directly related to the stress state along the root or fillet regions of the gear teeth.

Many parameters have been identified to impact tooth bending fatigue failures, including geometry of the gear teeth at their root region, the load distribution along the teeth, surface finish, material properties, residual stresses and operating conditions (speed, alignment, dynamic loads) [4] . Only one was distinguished here, this includes the main tooth strength factors that directly alter the tooth root stresses or so-called tooth root bending stress (TRBS) while the second group influences these stresses indirectly by changing the load distributions or input torque along the gear teeth that result in an uneven contact pattern due to its tooth surface contact stress (TSCS). A misalignment between engagement teeth that is recognized as one of the direct contributors to these causes of failure [5].

There are significant qualitative differences in the state of the tooth contact and bending strength of spur gears in misalignment conditions. While align spur gears are subject to loading conditions that cause a primarily uniaxial stress state, misalignments gears are subjected to complex loading schemes, which cause the gear tooth to experience multi-axial stress states. Significantly, this condition reduces the strength while increased the chances of bending fatigue failure, thus reducing bending fatigue life (BFL) of the gear system. In this study, an intensive works was conducted intends to focus on investigation the strength properties of tooth root bending stress and tooth surface contact stress of spur gear impact with axial misalignments conditions. Finite-element modelling is used to predict the root stresses and contact stress of TRBS and TSCS and the results was discussed intensively in correlate to the axial misalignments effects. 


\section{DEFINITION OF AXIAL MISALIGNMENTS}

Misalignment is probably the most common, single cause of failure. Due to misalignment, the pinion does not mesh properly with the gear during operation, and this leads to a high stress concentration at the surface and root of the gear teeth. Misalignment suggests a shifting of the theoretical position of pinion to wheel engagement from the actual position had happened when the gear pair is in their meshing position [6]. Several known causes of misalignments are due to deflection, errors during manufacture or assembly of the gear pair, or various other parameters. The occurrence of any of these actions typically alters the location of active contact face width directly to the tooth flank, which leads to undistributed large stresses. Hence, it may also increase the noise and vibration of the gear system. Misalignment in between spur gear teeth can occur in many forms and variants, but basically, it may be divided into three categories relatively to their coordinate of Line of Action (LOA).

As discussed by Houser [7], misalignment of the spur gear pair is categorized based on their cartesian coordinate system within their initial engagement position. Axial misalignment represents the deviation of the shaft offset from its nominal value. The offset happened at exactly in line of action LOA that allows a pinion to deviate in its nominal position to the wheel in global z-axis $\left(\mathrm{Z}_{\mathrm{G}}\right)$. Axial Misalignment (A represents the deviation of the shaft offset from its nominal value. The offset happened at exactly in line of action LOA that allows a pinion to deviate in its nominal position to the wheel in global $\mathrm{z}$-axis $\left(\mathrm{Z}_{\mathrm{G}}\right)$. A positive $\mathrm{A}$ is the offset for pinion in $-\mathrm{z}$ direction while negative $\mathrm{A}$ is in $+\mathrm{z}$ direction (Figure 1). This error is also referred to in the literature as the parallel offset misalignments [8].

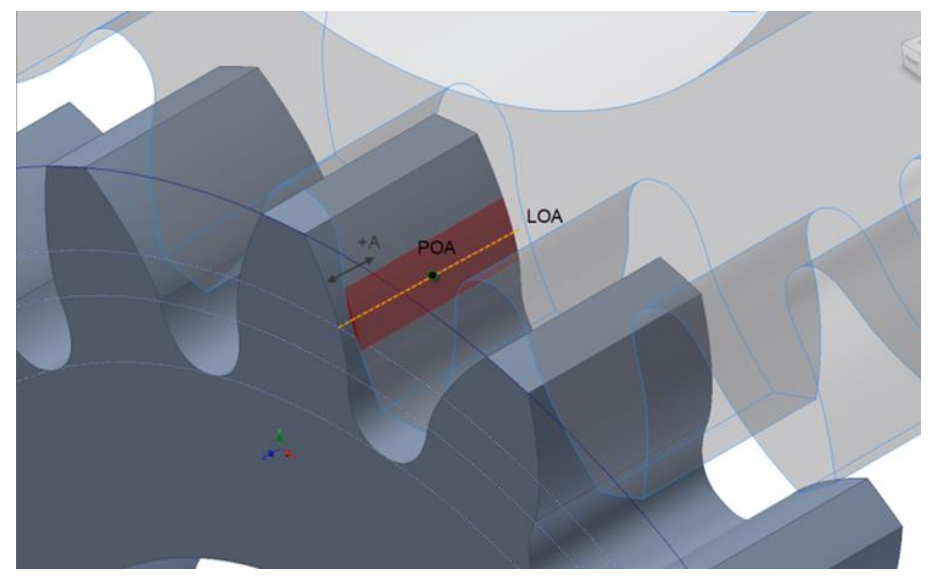

Figure 1: Definition of axial misalignment.

\section{FEM MODELING}

The FEM used in this study is based on commercially available finite element software [9]. The FEM modeling is presented in detail particularly on how relevant results are achieved as stated in the objective. The following flowchart in Figure 2 describes the procedures and the simulation process involved.

The geometrical CAD gear model with properties similar to [10] was constructed using Autodesk Inventor with .iam file format. It was then translated to Design Modeler compatible file models (.step file format or Step files) in ANSYS workbench using Automotive Design standard protocol 214. With these translation methods, parameters from the CAD .iam files are assured to have less than $0.00001 \mathrm{~mm}$ error when translated into STEP files. The format of a STEP-File is as defined in a published international standard ISO 10303-21 consisting of a 
Clear Text Encoding Exchange Structure, which is compatible to most finite element software [11]. ANSYS Workbench automatically locks all the length and coordinate units of the gears model assembly with the specified values defined in the CAD model, as used in Autodesk Inventor. No adjustment is necessary and exact coordinate CAD system can be transferred entirely with no parametric discrepancies or error to the finite element model.

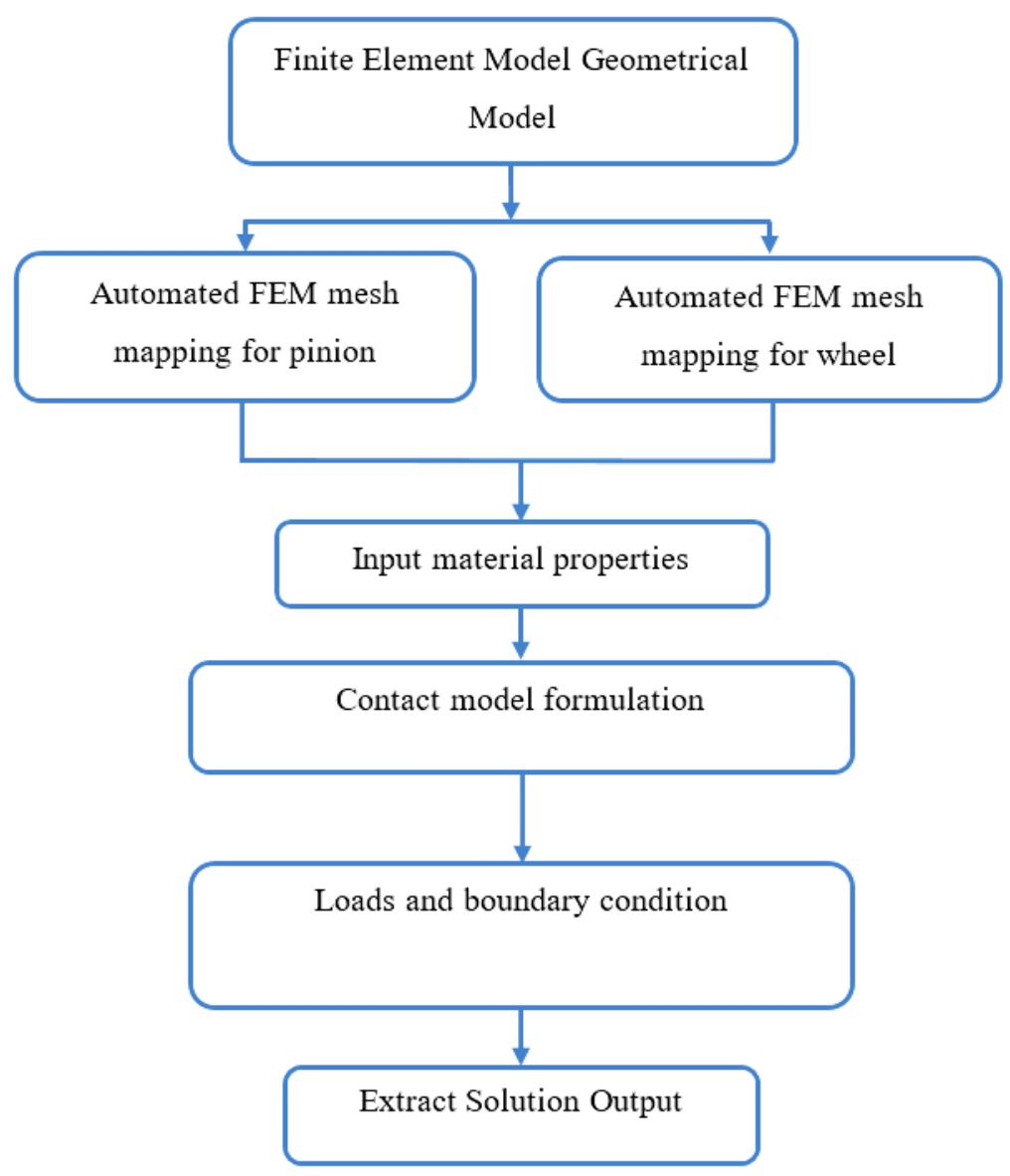

Figure 2: Flowchart of finite element modeling

Meshing and element selection in an FE model reflects the output result analysis [12-15]. In this model, a 20-noded isoperimetric hexahedral elements with shear modelling capability are used. This approach is combined with mapped automatic Mesh Tool generator in ASYS 15. It is applied by mapping the actual gear tooth solid body onto a pre-defined mesh template with several segments from a single gear tooth consisting of pinion and wheel. There are 64800 elements with 287008 node are created in this model.

With the gear geometry defined and meshing technique complete in ANSYS, other simulation properties can be assigned, such as the material definition. In this study, the gears are assumed to be manufactured using steel grade SAE/ANSI 1045 material [1]. To reduce the nonlinearity effect, material properties is set to be homogeneous and isotropic, therefore the stress-strain relationship remains elastic and the material properties are constant throughout the simulation process. This enables the output stresses and strains in FEM model to be determined through the input of Young's Modulus and the Poisson's Ratio only [12]. For this model, the Young's Modulus is set to $201 \mathrm{GPa}$ with Poisson's Ratio, 0.3, respectively.

The contact conditions are modelled using non-linear gap elements. The non-linear springs are placed in between contacting nodes to determine the transfer of forces between bodies [14]. When two gear tooth surfaces touch each other, such that they become mutually 
tangent, they are said to be in meshing contact. During meshing contact analysis, constraints that approximate contact are applied to various points on the contacting surfaces; the position and conditions of the constraints are determined through the contact discretization procedure selected, which in this case "true" surface-to-surface contact discretization.

In order to reduce the computational time, only three teeth are used during this simulation for both gears such as Figure 3. Three teeth FEM model of the gears has been used by several researchers [16-18]. The loads and boundary conditions are applied to both gears through their respective local centres, where the local centres are coupled to the rest of each gear body (pinion and wheel) using a kinematic link inside of the gear-to-shaft hole. Reference centre nodes M1 and M2, are defined on the pinion and wheel for the circular motion from the centre hole to the pinion tooth and from the wheel tooth to the wheel centre holes through their respective rigid surfaces.

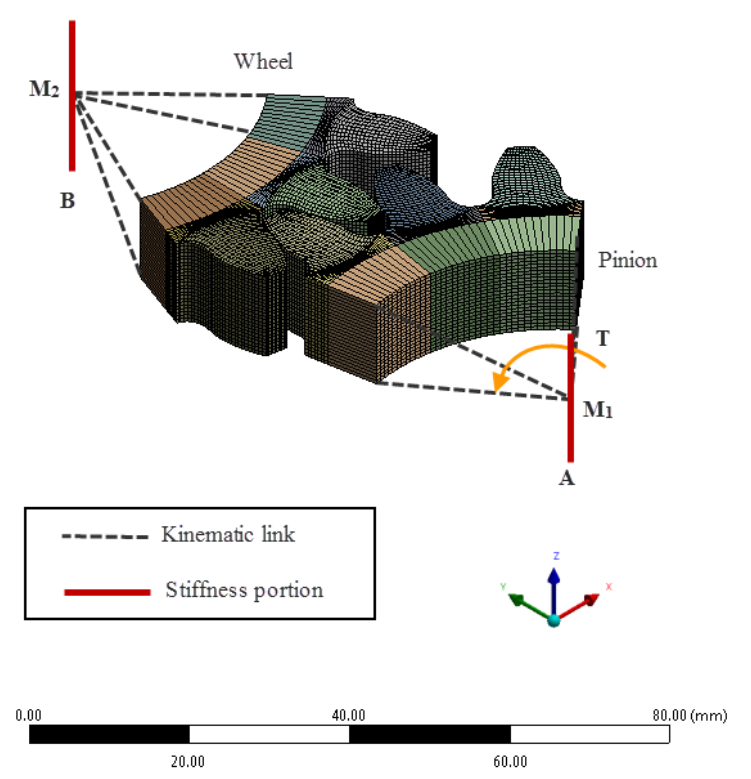

Figure 3: Load and boundary condition used on the FEM model.

This means that the nodal degrees-of-freedom (DOF) inside the gear-to-centre hole for pinion are governed by the DOF of the control node at the gear wheel centre. This node is constrained in all six DOF, and the rigid beam elements are connected between this node and the inside diameter of the gear and pinion. Both gears' central control points are restricted to allow only rotation about their local z-axes, where no rigid body motions are allowed. At this point, the finite element solution is ready to begin. To simulate one meshing period of the gear engagements, the magnitudes of loads (Torques) is applied constantly through the pinion side at stiffness portion A. This load is set with time steps to meet the quasi-static analysis requirements (slow motion). The rotation is then blocked at B with the same stiffness value at each of the steps. All $0.6 \mathrm{~s}$ time steps with $30^{\circ}$ pinion engagements position are used in this model. Table 1 shows the engagements position with time step values for one meshing period of the model.

The extraction of the TSCS is composed with the time steps of pinion rotation. For each rotation, the maximum TSCS are observed through the contact surface of the gear mesh. Maximum TSCS was then plotted to correlate the effect of misalignments to the contact strength of the tooth. Since 2006, the standard ISO [19] has been incorporated with the calculation of nominal tooth root stress. According to the standard-method B, a critical tooth root section is 
determined by the angle $\varphi=30^{\circ}$ between the tangent to the tooth fillet and the tooth centre line, considering the loading at the outer point of single pair tooth contact. It's also known as Hofer's critical section. However, when axial misalignments happened, these locations may be shifted to other section of the tooth region. Thus the data extracted from this model was based on time varying stress of TRBS. Maximum TRBS was measured in between the time steps of pinion rotation.

Table 1. Engagement positions with time step values for one meshing period of the model.

\begin{tabular}{ccc}
\hline $\begin{array}{c}\text { Pinion } \\
\text { Rotation(degree) }\end{array}$ & $\begin{array}{c}\text { Time Steps } \\
\text { (s) }\end{array}$ & \begin{tabular}{c} 
Engagement Position \\
\hline 1
\end{tabular} \\
0.02 & Double Tooth Contact (DTC) \\
2 & 0.04 & DTC \\
3.5 & 0.07 & DTC \\
5 & 0.1 & DTC \\
6 & 0.12 & DTC \\
7 & 0.14 & DTC \\
8.5 & 0.17 & DTC \\
10 & 0.2 & DTC \\
11 & 0.22 & Lowest point single tooth contact \\
12 & 0.24 & Single tooth Contact (STC) \\
13.5 & 0.27 & STC \\
15 & 0.3 & STC \\
16 & 0.32 & STC \\
17 & 0.34 & STC \\
18.5 & 0.37 & Pitch Circle Diameter (PCD) - STC \\
20 & 0.4 & DTC \\
21 & 0.42 & DTC \\
22 & 0.44 & DTC \\
23.5 & 0.47 & DTC \\
25 & 0.5 & DTC \\
26 & 0.52 & DTC \\
27 & 0.54 & DTC \\
28.5 & 0.57 & DTC \\
30 & 0.6 & DTC \\
\hline & &
\end{tabular}

\section{RESULT AND DISCUSSION}

Result extracted from the FEM model was presented separately with respects to their effects on TSCS and TRBS for the gear in axial misalignments condition.

\section{Effect of axial misalignment to TSCS}

As illustrated in Figure 4, the TSCS for the pinion was plotted as the function of pinion rotation and time steps engagement with different axial misalignments from 0.1 to $0.5 \mathrm{~mm}$ under Torque $=50 \mathrm{Nm}$. As can be seen, when the rotation began $\left(\mathrm{d}_{\text {int }}\right)$ at time $0.02 \mathrm{~s}$ to $0.2 \mathrm{~s}$, TSCS was in the range between $45-109 \mathrm{MPa}$. After the pinion passed through the LPSTC, the stress was increased from $109 \mathrm{MPa}$ to $141.14 \mathrm{MPa}$. When the rotation passed through PCD, the maximum 
TSCS for the pinion was recorded at $18.5^{\circ}$, time $=0.37 \mathrm{~s}$ with $144.24 \mathrm{MPa}$. Shortly after that the engagement continued through HPSTC location, where DTC came in action before the mesh cycles continued to the next teeth engagement.

Almost the same trend happened for the wheel as depicted in Figure 5. When DTC is in action, TSCS was between $37-100 \mathrm{MPa}$-lower compared to the pinion. Instantly after the rotation continued, the value of TSCS increased to almost 30\% in the range between $54-139$ MPa. In between time $0.4 \mathrm{~s}$ and $0.6 \mathrm{~s}$, DTC action caused the stress to reduce for about $15 \%$. Maximum TSCS was observed at $0.22 \mathrm{~s}$ when the pinion rotation was at $11^{0}$. This is where the worst loading position can be located for the wheel. The comparison between maximum TSCS of the pinion and wheel was demonstrated in Figure 6. From the figure it is clear that axial misalignment had caused a transverse proportional effect to TSCS. Higher amounts of axial misalignments will reduce TSCS. Correspondingly, this finding was consistent with discussion from several researchers [20].

As stated before, since the axial misalignment is the offset of the pinion surface from aligned axis to the wheel, the decrement in contact area of the pinion and wheel face proved it influenced the contact pressure once the gear rotated in its position. Contact pressure application on the contact area of the tooth face leads to reduction TSCS and contact deformation. Thus this effects will decrease the contact area across the tooth face - leading to reduced contact pressure owing to the offsetting of the POA applied when the gear rotates.

The variation in the point of action (POA) through the contact is due to the offset of the teeth as they travel through the contact surface. For example, as two teeth enter into contact, the load is transmitted through the tip of tooth 1 and the root of tooth 2 . The deformation of tooth 1 is greater than tooth 2 and since an axial misalignment is imposed, tooth 1 is offset more than tooth 2 and the POA moves towards the leading edge. As the teeth moves through the contact the load begins to move to the root of tooth 1 and the tip of tooth 2 , therefore tooth 2 deforms more than tooth 1 and the POA moves accordingly. This results also clarifies that the contact pressure on the drive side (pinion) is slightly higher than on the coast side (wheel) in axial misalignments and therefore increases the TSCS for the pinion compared to the wheel. The effect is then reversed where more deformation is seen on the coast side, which suggests that the offsetting direction has changed and the POA moved as a result of this.

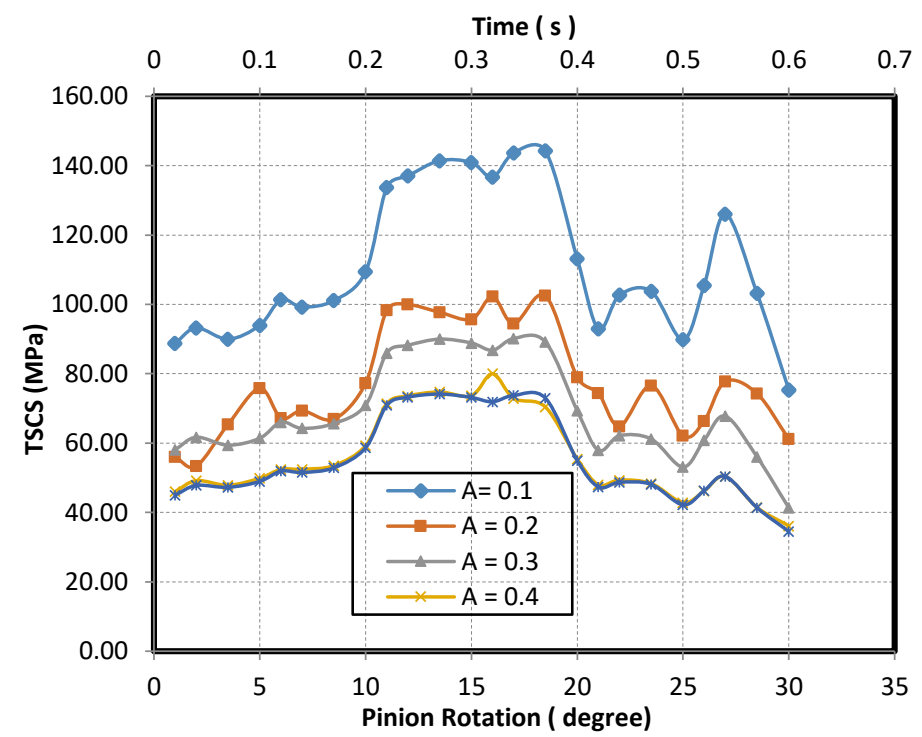

Figure 4: TSCS for pinion in axial misalignments at $\mathrm{T}=50 \mathrm{Nm}$ 


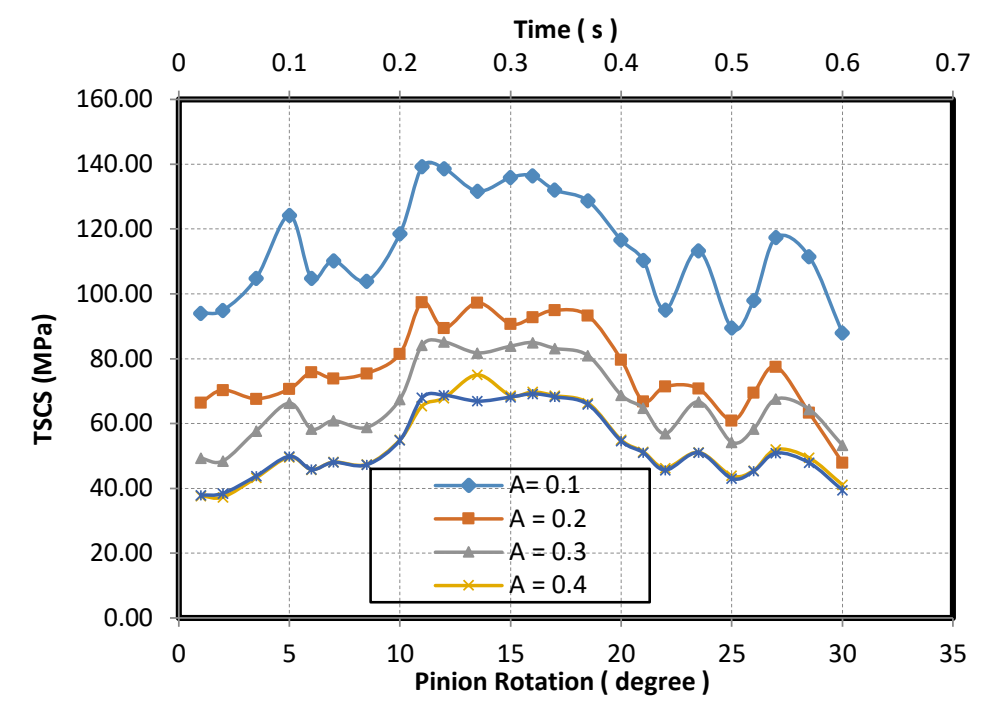

Figure 5: TSCS for wheel in axial misalignments at $\mathrm{T}=50 \mathrm{Nm}$

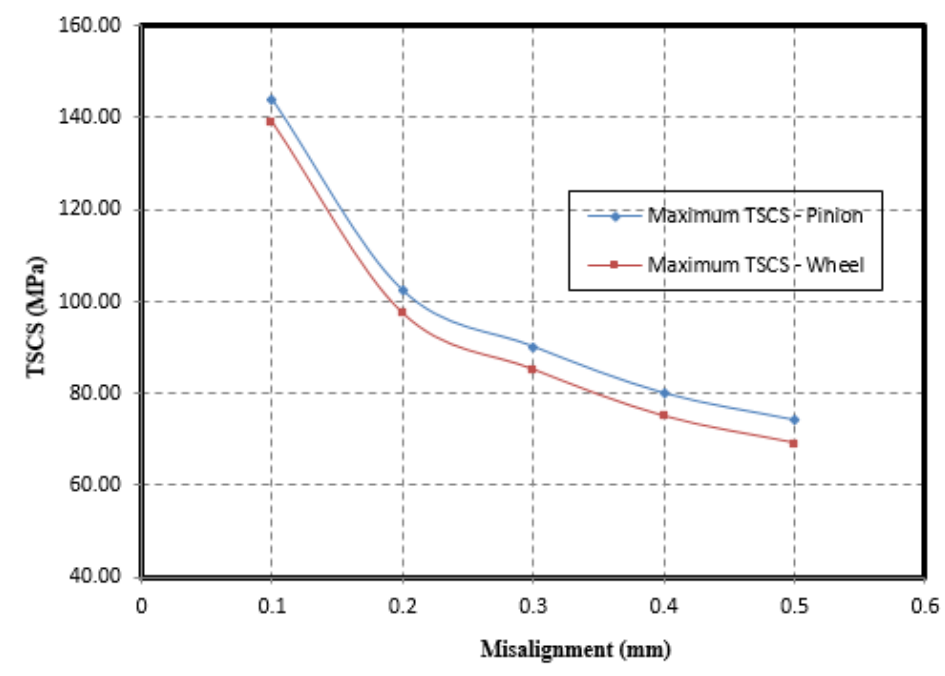

Figure 6: Effect of axial misalignment to the TSCS between pinion and wheel at $\mathrm{T}=50 \mathrm{Nm}$

\section{Effect of axial misalignment to TSCS}

Figure 7 shows the effect of axial misalignment to the TRBS of pinion for one mesh cycle at Torque $=50 \mathrm{Nm}$. Generally, TRBS shows a constant distribution with different amounts of axial misalignments. At first contact, $(\mathrm{t}=0.02)$ TRBS was measured between 27-32 MPa for different input of axial misalignment. In between $(0.2-0.4 \mathrm{~s})$ when the pinion rotated at $100-20^{\circ}$; the single tooth contact action (STC) caused TRBS to become higher from 36.66 to 54 at MPa. This is the range where the worst loading position took place at time $0.37 \mathrm{~s}$. Once after the mesh cycle continued to the pinion rotation at $20^{\circ}$ to $30^{\circ}$, the double tooth contact action (DTC) caused TRBS to reduce about $30 \%$ before the mesh cycle completes into the next tooth engagement.

Almost the same trend was observed in Figure 8 where the TRBS of the wheel in axial misalignments was plotted in one-mesh cycles. From the figure, the maximum TRBS recorded happened at time $0.22 \mathrm{~s}$, which was different compared to the pinion. It was expected that, at this moment the worst loading position was shifted from the pinion to the wheel. This is the time where LOA for the wheel contact was at a higher position in compared to the pinion. 
Application of contact pressure then produced higher force since the nominal length of the LOA happened at full contact face width of the wheel tooth. The force-length action consequently will result in higher bending load for the wheel teeth.

It was predicted that since axial misalignment moved the contact area towards one edge of the tooth, and away from the other, that the introduction of axial misalignment will generate moments at the face width direction about the gear centre of mass. Since the angle and direction of the LOA were unchanged, the normal LOA forces will remain constant; where the forces will be distributed respectively across the misalignment range. This result corroborates the assumption that increased axial misalignment has little effect on the TRBS, however it may lead to greater variation in the pressure angle and the composition of the LOA reaction forces.

In order to correlate the effect of axial misalignment to the TRBS for the pinion and wheel, the maximum value of TRBS was plotted against the axial misalignments such as Figure 9. It is known that the bending stress is the main components in the gear tooth strength. From the figure, result shows that when the amount of axial misalignment $0.1 \mathrm{~mm}$, maximum TRBS is $54.021 \mathrm{MPa}$ for pinion and $53.908 \mathrm{MPa}$ for the wheel. Hence, when the value of axial misalignments $0.5 \mathrm{~mm}$, maximum TRBS is $54.447 \mathrm{MPa}$ for pinion and $54.334 \mathrm{MPa}$ for the wheel. For this reason, it is fair to say that TRBS was proportionally increasing with the increase of axial misalignment. It was also noticeable that the pinion TRBS was higher compared to the wheel. Theoretically, this was supported by [21,22] which described the correlation of the bending stress to the axial misalignment, i.e., offsetting assembly error of the gear pair. In conclusion, axial misalignments will cause an increase in TRBS which apparently reduces the strength of the gear tooth.

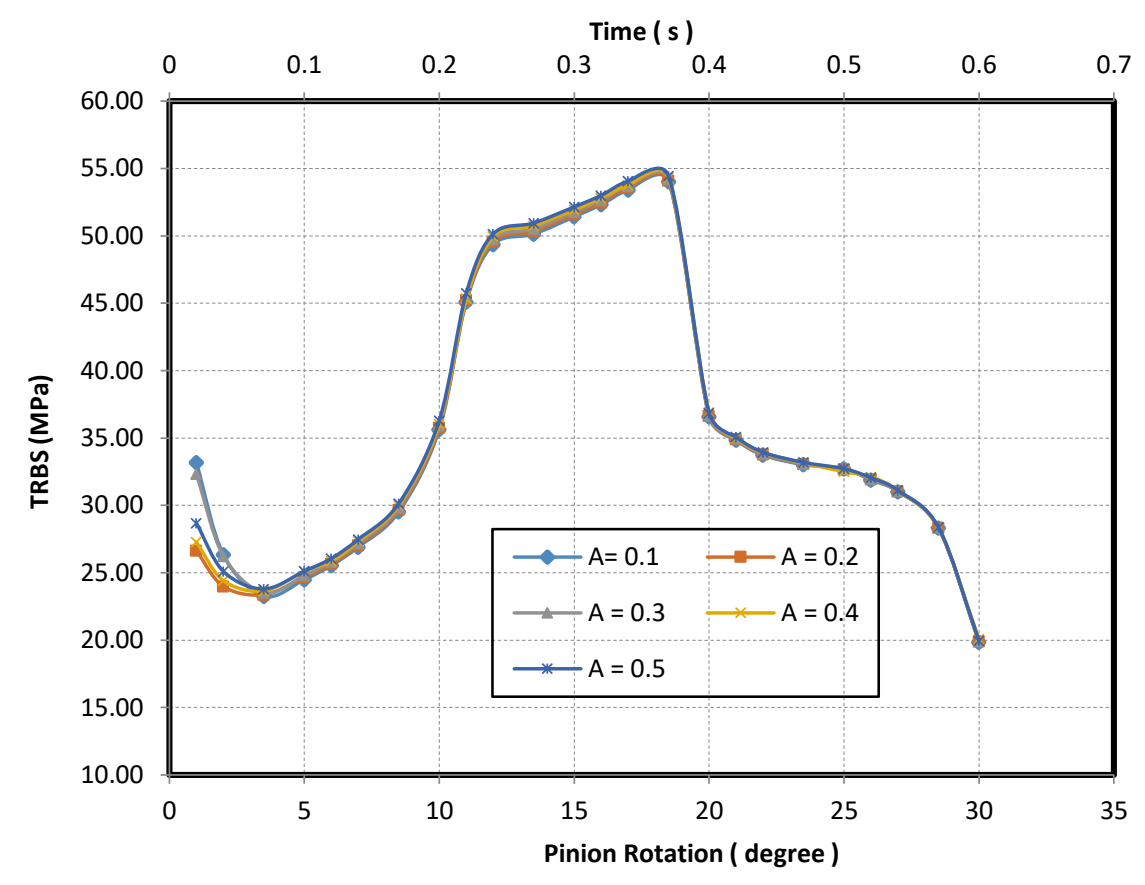

Figure 7: TRBS for pinion in axial misalignments at $\mathrm{T}=50 \mathrm{Nm}$ 


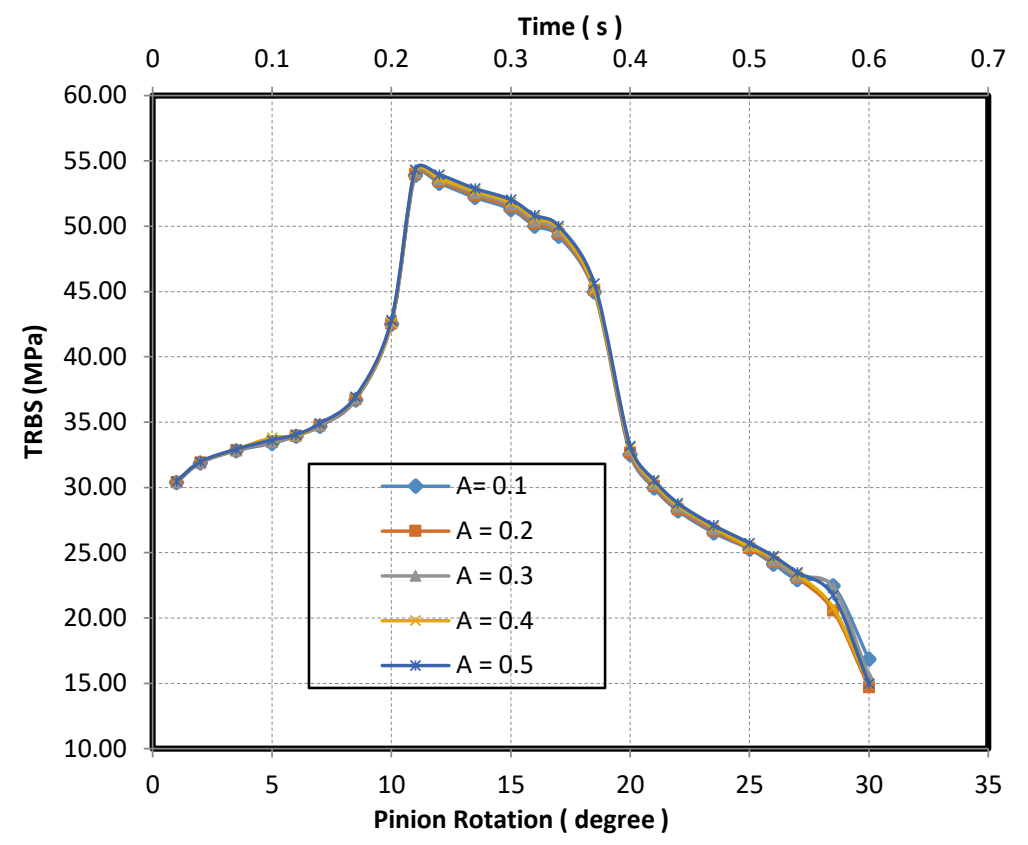

Figure 8: TRBS for wheel axial misalignments at $\mathrm{T}=50 \mathrm{Nm}$

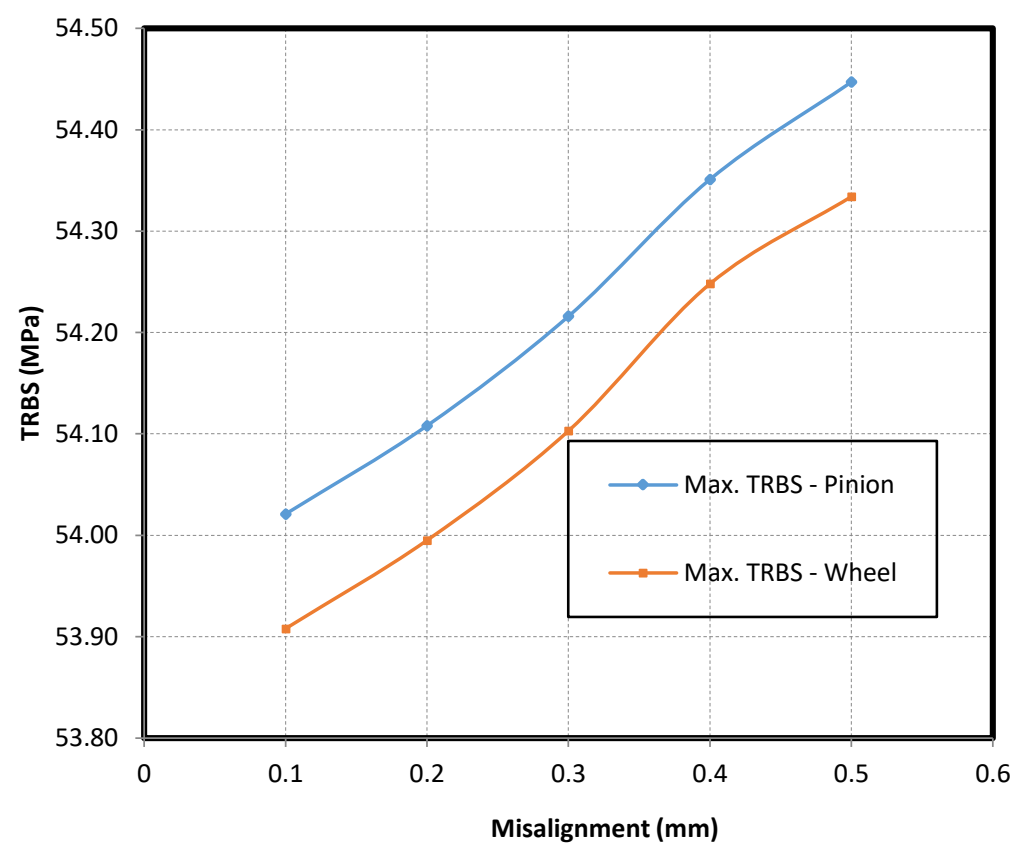

Figure 9: Effect of axial misalignment to the TRBS between pinion and wheel at $\mathrm{T}=50 \mathrm{Nm}$

\section{CONCLUSION}

In this paper, a finite-element method was used to investigate the effects of axial misalignments to strength properties (TSCS and TRBS) of the spur gear. This model was constructed based on gear CAD model generated from an Autodesk Inventor gear design generator using quasi statics approach. The investigation leads to a significant finding that axial misalignment results showed that axial misalignments do impact upon strength the strength properties of the gears. 
Tooth surface contact stress and tooth root bending stress showed between $5 \%$ to $15 \%$ incremental trend at different critical location while the strength reducing simultaneously with the application of axial misalignments. The pinion showed a weakening trend compare to the wheel when the application of axial misalignments took place. A series of verification tests according to [23] is suggested to validate the finite-element model thus concluded that this research had achieved its main objectives where the strength properties of tooth surface contact stress and tooth root bending stress of the gear in axial misalignments gear were successfully investigated.

\section{ACKNOWLEDGEMENTS}

The authors would like to acknowledge Universiti Teknologi PETRONAS and Kolej Komuniti Kluang Johor for providing facilities and supports throughout this research.

\section{REFERENCES}

[1] Radzevich SP, Dudley DW. Handbook of practical gear design: CRC press; 1994.

[2] Juvinall RC, Marshek KM. Fundamentals of machine component design: John Wiley \& Sons New York; 2006.

[3] Litvin FL, Lian Q, Kapelevich AL. Asymmetric modified spur gear drives: reduction of noise, localization of contact, simulation of meshing and stress analysis. Computer Methods in Applied Mechanics and Engineering. 2000;188:363-90.

[4] McIntire W, Malott R, Lyon T. Bending Strength of Spur and Helical Gear Teeth. SemiAnnual Meeting of the American Gear Manufacturers Association1967.

[5] McVlittie D. Misalignment No Beauty in Gearsets. Gear technology. USA: Randall Publications LLC 1996-2015; 1991. p. 11.

[6] Lias M, Rao T, Awang M, Khan M. The Stress Distribution of Gear Tooth Due to Axial Misalignment Condition. Journal of Applied Sciences. 2012;12:2404-410.

[7] Houser D, Harianto J, Talbot D. Gear mesh misalignment. Gear Solutions (June 2006). 2006:34-43.

[8] Curà F, Mura A, Gravina M. Load distribution in spline coupling teeth with parallel offset misalignment. Proceedings of the Institution of Mechanical Engineers, Part C: Journal of Mechanical Engineering Science. 2013;227:2195-205.

[9] Kadirgama K, Rahman MM, Ismail AR, Bakar RA. Finite element analysis of HASTELLOY C-22HS in end milling. Journal of Mechanical Engineering and Sciences. 2011;1:37-46

[10] Lias M, Sharif Z, Awang M, Jailani A, Warap H. Quasi-Static Modeling of Spur Gear Time Varying Strength Analysis. ARPN Journal of Engineering and Applied Sciences . 2016;12:1938-47.

[11] Lawrence KL. ANSYS Workbench Tutorial Release 14: SDC Publications; 2012.

[12] $\mathrm{Hu} Y$, Shao Y, Chen Z, Zuo MJ. Transient meshing performance of gears with different modification coefficients and helical angles using explicit dynamic FEA. Mechanical systems and signal processing. 2011;25:1786-802.

[13] Siswanto WA, Nagentrau M, Tobi M, Latif A. Prediction of residual stress using explicit finite element method. Journal of Mechanical Engineering and Sciences . 2015; $9: 1556$ -70 .

[14] Kaveh A. Computational structural analysis and finite element methods: Springer; 2014. 
[15] Mohamed MA, Manurung YH, Ghazali FA, Karim AA. Finite element-based fatigue life prediction of a load-carrying cruciform joint. Journal of Mechanical Engineering and Sciences. $2015 ; 8: 1414-25$.

[16] Jones R, Mao K, Phang A, Allen B. Effects of linear and angular misalignment on a spur gear pair. Insight-Non-Destructive Testing and Condition Monitoring. 2011;53:420-5.

[17] Guingand M, De Vaujany J-P, Jacquin C-Y. Quasi-static analysis of a face gear under torque. Computer methods in applied mechanics and engineering. 2005;194:4301-18.

[18] Hwang S-C, Lee J-H, Lee D-H, Han S-H, Lee K-H. Contact stress analysis for a pair of mating gears. Mathematical and Computer Modelling. 2013;57:40-9.

[19] Kawalec A, Wiktor J, Ceglarek D. Comparative analysis of tooth-root strength using ISO and AGMA standards in spur and helical gears with FEM-based verification. Journal of Mechanical Design. 2006;128:1141-58.

[20] STANDARD B, ISO B. Calculation of load capacity of spur and helical gears - 2008.

[21] Atanasovska I, Nikolic V. 3D spur gear FEM model for the numerical calculation of face load factor. Mech, Autom Control Rob. 2006;6:131-43.

[22] Irfan M. Meta Modeling of Transmission Error for Spur, Helical and Planetary Gears for Wind Turbine Application. Chalmers University of Technology; 2013.

[23] SAE I. Single Tooth Gear Bending Fatigue Test. Warrendale, Pennsylvania Troy, Michigan: SAE International Publisher; 1997. 